\title{
Prevalence of Neck Pain Among Otolaryngologists
}

Nawal Abd El-Raouf Abou-Shady ${ }^{1}$, Rasha M. El Rewainy ${ }^{1}$,

Walaa E. El-Den Mohamed Mustafa ${ }^{1}$, Ibrahim M. Hamoda ${ }^{2}$.

${ }^{1}$ Department of Neuromuscular Disorders and its Surgery, Faculty of Physical Therapy, Cairo University,

${ }^{2}$ Department of Neuromuscular Disorders and its Surgery, Faculty of Physical Therapy, Kafr El-Sheikh University.

*Corresponding author: Walaa Essam El-Den Mohamed Mustafa, E-mail: drmuslima615@ gmail.com, Mobile: (0020)1005789709

\begin{abstract}
Background: otolaryngologists spend their workdays in performing markedly precise procedures in small works places i.e. the patients' ear, nose and throat. Due to this, they frequently adopt awkward neck, back and shoulder postures while using devices like otoscope, endoscope and microscope. So, the otolaryngologists' job profile puts them at high risk for musculoskeletal disorders like neck pain. Purpose: of the study was to investigate the prevalence of work-related neck pain among otolaryngologists - head and neck surgeons. Patients and Methods: specific questionnaire based on Visual Analog Scale and Neck Disability Index was given to one hundred otolaryngologists, head and neck surgeons of both gender, age from 30 to 40 years selected from ENT Departments in Hospitals of Ministry of Health. Results: The statistical analysis revealed that the prevalence of work-related neck pain among otolaryngologists was (69\%). Regarding the severity of pain, (80\%) reported pain as mild pain while (20\%) reported pain as moderate. Conclusion: It could be concluded that work related neck pain is common among Egyptian Otolaryngologists, making otolaryngologists at a high-risk group. There is a need to improve ergonomics in the clinical and operative room settings and to educate otolaryngologists on ergonomic principles.
\end{abstract}

Keywords: Neck pain, Otolaryngologists, Musculoskeletal disorders

\section{INTRODUCTION}

Work-related musculoskeletal disorders are prone to occur, when there is a mismatch between physical requirements and physical capacity. Otolaryngologists are not immune to musculoskeletal strain and injury, Work-place related musculoskeletal symptoms, particularly in the neck and shoulders, are common among otolaryngologists ${ }^{(\mathbf{1})}$.

There are increased reports of prevalence of workrelated musculoskeletal disorders (WRMSDs) in surgeons performing minimal access surgeries. Because of the character of the specialty, otolaryngologists spend their workdays in performing markedly precise procedures in small works places i.e. the patients' ear, nose and throat. Due to this, they frequently adopt awkward neck, back and shoulder postures while using devices like otoscope, endoscope and microscope ${ }^{(2)}$.

Neck pain is one of the most frequent complaints among the general population, especially for health care professionals and otolaryngologists, who are likely to develop work-related neck pain ${ }^{(3)}$.

Neck pain is second only to low back pain as the most common musculoskeletal disorder in population surveys and primary care and as in low back pain, it poses a significant health and economic burden and a frequent source of disability ${ }^{(4)}$.

As a point of reference, epidemiological studies have reported: Point prevalence of neck pain to be $4.9 \%$ (females: 5.8\%; males: $4.0 \%)^{(5)}$. Annual prevalence ranging between $30 \%$ and $50 \%{ }^{(6)}$, with one systematic review reporting a mean rate of $37.2 \%{ }^{(7)}$. Lifetime prevalence to be between $22 \%$ to $70 \%{ }^{(8)}$.

\section{Purpose of the study:}

The purpose of the study was to investigate the prevalence of work-related neck pain among otolaryngologists, head and neck surgeons and to determine risk factors of demographic and workload data.

\section{SUBJECTS AND METHODS}

This cross-section study included a total of one hundred otolaryngologists, head and neck surgeons, selected from E.N.T Departments in Hospitals of Ministry of Health in the period from January 2019 to January 2020.

Ethical approval: the study was approved by the Ethics board of Cairo University No. P.T.REC/012/002667. Written informed consent of all the subjects was obtained.

\section{Inclusion criteria}

1) Age ranged from $30-40$ years.

2) Body mass index (BMI) ranged from 25 to $35\left(\mathrm{~kg} / \mathrm{m}^{2}\right)$.

3) Both genders are involved in the study.

\section{Exclusion criteria:}

1) History of bone diseases.

2) Suffering of cervical radiculopathy before working as otolaryngologist.

3) Head or cervical subluxation or fracture.

4) Systemic disease as rheumatoid arthritis.

5) Head or cervical surgery.

6) Pregnant women.

\section{Materials:}

1) Recording data sheet. ( Name, Gender, Age, Years of experiences, Work status, Type of chair, Average 
ejhm.journals.ekb.eg

number of working hours per week, Average number of cases at ENT clinic per week, Average number of hours of clinical work per week, Average number of operations performed per week, Average number of operating hours per week, Dominant hand, Direct question about having neck pain).

2) Weight and Height measurements: were measured to calculate BMI.

3) Visual Analog Scale:

a. The visual Analog Scale (VAS) is considered to be one of the available methods for the estimation of the intensity of pain.

b. Pain intensity is determined by the length of the line as measured from the left hand side to the point marked. The VAS has been validated in measuring pain $^{(9)}$.

4) Neck Disability Index (NDI): The NDI is a modification of the Oswestry Low Back Pain Disability Index. It is a patient-completed, condition-specific functional status questionnaire with 10 items including pain, personal care, lifting, reading, headaches, concentration, work, driving, sleeping and recreation. The NDI has sufficient support and usefulness to retain its current status as the most commonly used self-report measure for neck pain $^{(\mathbf{1 0})}$.

\section{Procedure:}

A self-administered questionnaire was used for data collection. The questionnaire was offered in both hard and soft electronic copy.

The questionnaire had three main components. The first part was designed to collect demographic and workload data, the second part based on Visual Analog Scale (VAS) for the estimation of the intensity of pain and the last part included the Neck Disability Index (NDI) which indicated pain intensity. It had 10 items: pain intensity, personal care, sleeping, lifting, driving, headache, recreation, , concentration, reading, and work.

The questionnaire and data sheet were delivered personally and through e-mails to the otolaryngologists and head and neck surgeons, then the aim of the study was explained to them, at the final the questionnaire was collected upon answering completion.

There was an informed consent of scientific publication of the questionnaire provided data as a part of the questionnaire.

\section{Statistical analysis}

Descriptive statistics of mean, standard deviation, frequencies, percentages and confidence interval (CI) were utilized in presenting the subjects demographic and measured data. Quantitative variables were summarized using mean and standard deviation while categorical variables were summarized using frequencies and percentage. Chi-square statistics was utilized to examine associations between neck pain prevalence and subject characteristics and with workloads. Logistic regression analysis was used in determining the variables that predict neck pain among the participants. The level of significance for all statistical tests was set at $p<0.05$. All statistical measures were performed through the statistical package for social studies (SPSS) version 25 for windows.

\section{RESULTS}

One hundred subjects of ENT surgeons from different Egypt governate participated in this study. The mean \pm SD age of the study group was $33.03 \pm$ 2.91years with minimum of 30 years and maximum of 40 years. The mean \pm SD BMI of the study group $27.68 \pm 2.67 \mathrm{~kg} / \mathrm{m}^{2}$ with minimum of $19 \mathrm{~kg} / \mathrm{m}^{2}$ and maximum of $33 \mathrm{~kg} / \mathrm{m}^{2}$. Table (1) showed the subject characteristics.

Table (1): Participants' characteristics.

\begin{tabular}{|l|c|c|}
\hline & N & \% \\
\hline Sex & & \\
Females & 41 & $41 \%$ \\
Males & 59 & $59 \%$ \\
\hline Dominant hand & & \\
Right & 90 & $90 \%$ \\
Left & 10 & $10 \%$ \\
\hline Work status & & \\
Full time & 60 & $60 \%$ \\
Part time & 40 & $40 \%$ \\
\hline Years of experience & & \\
4- 7 years & 61 & $61 \%$ \\
8-16 years & 39 & $39 \%$ \\
\hline Clinical working hours/week & & \\
10- 40 hours/week & 63 & $63 \%$ \\
41-60 hours/week & 37 & $37 \%$ \\
\hline Number of cases /week & & \\
10- 80 cases /week & 53 & $53 \%$ \\
$80-250$ cases /week & 47 & $47 \%$ \\
\hline $\begin{array}{l}\text { Number of operations/week } \\
\text { 0-4 operations/week }\end{array}$ & 60 & $60 \%$ \\
5-30 operations/week & 40 & $40 \%$ \\
\hline Number of operating hours/week & & \\
0-5 operating hours/week & 58 & $58 \%$ \\
6-30 operating hours/week & 42 & $42 \%$ \\
\hline
\end{tabular}

Prevalence of neck pain among participants:

The lifetime prevalence of work-related neck pain of the study group was $69 \%$ with $95 \%$ CI of 59.37- 77.22\%. The twelve-month prevalence was $44 \%$ with $95 \%$ CI of $34.67-53.77 \%$. The point prevalence of work-related neck pain was $28 \%$ with $95 \%$ CI of $20.13-37.48 \%$. (table 2).

Table (2): Prevalence of neck pain of the study group. 
ejhm.journals.ekb.eg

\begin{tabular}{|l|l|l|}
\hline & $\begin{array}{l}\text { Prevalence of } \\
\text { neck pain }\end{array}$ & $\mathbf{9 5 \%}$ CI \\
\hline $\begin{array}{l}\text { Lifetime prevalence } \\
\text { Twelve-month } \\
\text { prevalence }\end{array}$ & $44(69 \%)$ & $59.37-77.22 \%$ \\
Point prevalence & $28(28 \%)$ & $34.67-53.77 \%$ \\
\hline
\end{tabular}

CI: Confidence interval

\section{Perception of neck pain:}

The majority of subjects suffered from neck pain, $55(80 \%)$, reported the severity as mild pain while 14 (20\%) subjects reported pain as moderate. The scores of NDI in subjects with neck pain revealed that $9(13 \%)$ subjects had no disability, $50(72.5 \%)$ had minimal disability and $10(14.5 \%)$ subjects had moderate disability. (table 3).

Table (3): Perception of neck pain.

\begin{tabular}{|l|l|l|l|}
\hline & & $\mathbf{N}$ & $\%$ \\
\hline Severity & Mild & 55 & $80 \%$ \\
& Moderate & 14 & $20 \%$ \\
\hline Functional & No disability (0-8\%) & 9 & $13 \%$ \\
disability. & Minimal disability (10-28\% & 50 & $72.5 \%$ \\
& Moderate disability (30-48\% & 10 & $14.5 \%$ \\
\hline
\end{tabular}

Association between twelve-month neck pain and subject characteristics and workloads:

There was a significant increase in the prevalence of work-related neck pain in right-handed compared with that in left-handed $(\mathrm{p}=0.02)$, significant increase in the prevalence of in subjects with 8-16 experience years compared with that in subjects with 4- 7 experience years $(\mathrm{p}=0.005)$ and significant increase in the prevalence of in subjects with 41- 60 clinical working hours/week compared with that in subjects with 10- 40 clinical working hours/week $(p=0.005)$.

Also, there was a significant increase in the prevalence of work-related neck pain in subjects received 81- 250 cases/week compared with that in subjects received 10- 80 cases/week $(p=0.003)$, significant increase in the prevalence in subjects with 5- 30 operations/week compared with that in subjects with 0 - 4 operations/week $(\mathrm{p}=0.008)$ and significant increase in the prevalence in subjects with 6- 30 operating hours/week compared with that in subjects with 0 - 5 operating hours/week $(\mathrm{p}=0.008)$.

There was no significant association between work-related neck pain with sex and work status ( $p$ > 0.05). (table 4).

Table (4): The frequency distribution of neck pain and association between neck pain and subject characteristics and workloads.

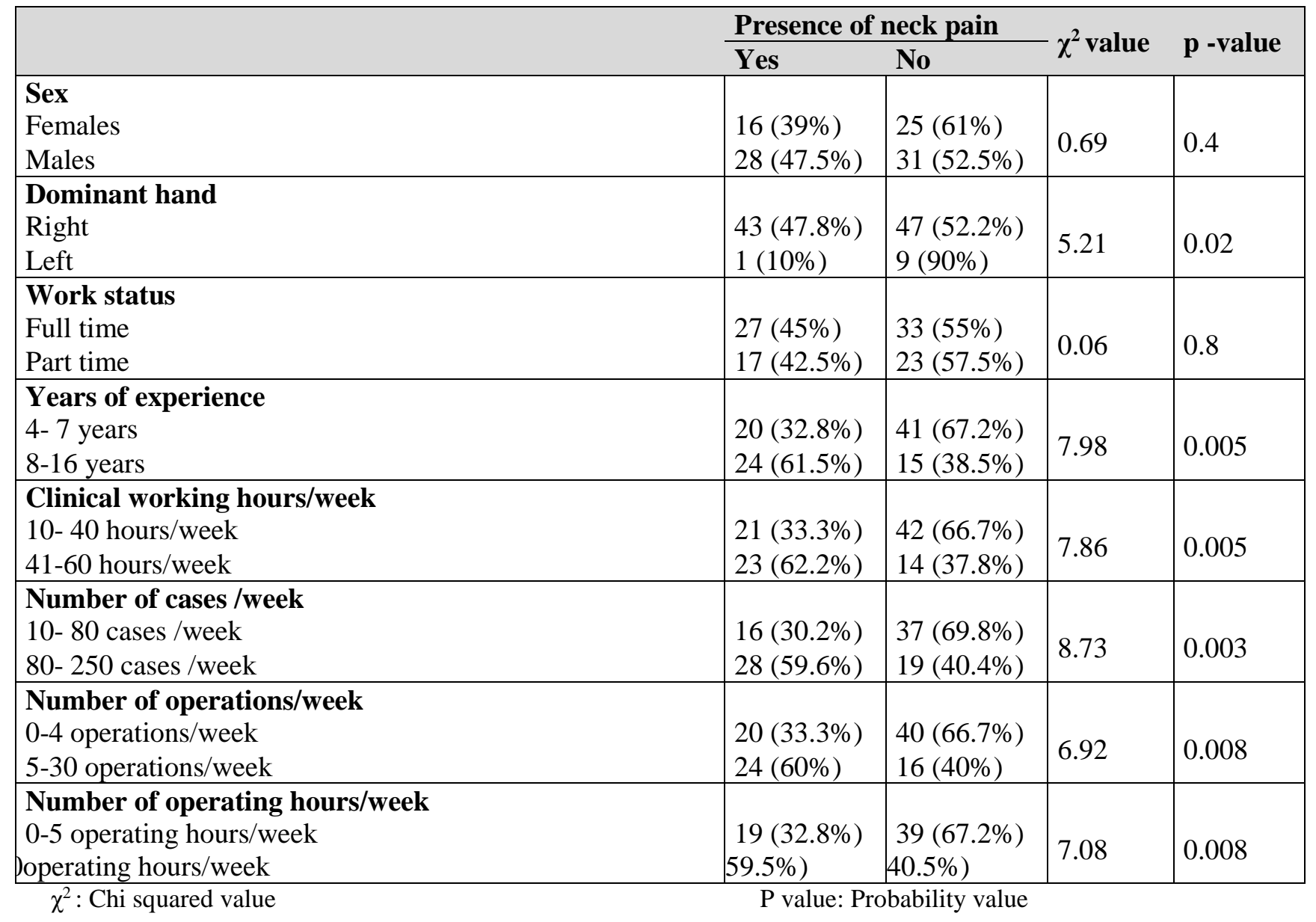


ejhm.journals.ekb.eg

\section{Prediction of neck pain among the participants}

A Binary logistic regression was performed to determine the variables that predict neck pain among the participants. Years of experience, clinical working hours, number of cases /week, number of operations/week, number of operating hours/week were significant predictors for neck pain while sex, hand dominance, and work status were not significant predictors for neck pain. (table 5).

Table (5): Predictors of neck pain among participants.

\begin{tabular}{|l|l|l|l|}
\hline Variables & Odds ratio & 95\% CI & p-value \\
\hline Sex & 0.7 & $0.31-1.59$ & 0.4 \\
Hand dominance & 0.12 & $0.01-0.99$ & 0.05 \\
Work status & 0.9 & $0.4-2.02$ & 0.8 \\
Years of experience & 0.76 & 0.66 .0 .88 & 0.0001 \\
Clinical working hours/week & 0.94 & $0.9-0.98$ & 0.005 \\
Number of cases /week & 0.98 & $0.98-0.99$ & 0.006 \\
Number of operations/week & 0.87 & $0.74-0.96$ & 0.01 \\
Number of operating hours/week & 0.9 & $0.83-0.97$ & 0.01 \\
\hline
\end{tabular}

CI: Confidence interval

\section{DISCUSSION}

Neck pain is a frequent complaint in the general population, with a reported prevalence of $0.4 \%$ to $86.8 \%$ worldwide ${ }^{(11)}$. Other symptoms such as headaches, stiffness, or even paresthesia may be present with neck pain. Otolaryngologists are more vulnerable to neck pain due to the nature of their work ${ }^{(\mathbf{1 1})}$. In this study, we asked otolaryngologists whether neck pain affected their daily lives and work using the NDI.

The results of the current study showed that otolaryngologists in Egypt were at high risk of developing neck pain as their prevalence of neck pain was $69 \%$. This may be attributed to sustained postures, awkward postures, inadequate breaks and prolonged time of procedures. This results comes in agreement with the findings of Alem et al. ${ }^{(3)}$ who found that the prevalence of otolaryngologists neck pain was $65.2 \%$ in Saudi Arabia.

The present study also agrees with study by BolducBégin et al. ${ }^{(12)}$ on otolaryngologists and head and neck surgeons in Canada which revealed prevalence of neck pain as $64.3 \%$ in Otolaryngology Head and Neck Surgery (OHNS) and $59.7 \%$ in pediatric otolaryngologists.

A study about Endoscopic sinus surgery and musculoskeletal symptoms found that prevalence of neck pain was $60.3 \%$ with paresthesia in $12.8 \%$. Intensity of pain was $53.9 \%$ as mild, $37.5 \%$ moderate and $8.5 \%$ reported sever pain Rimmer et al. ${ }^{(13)}$.

Also, Wong et al. ${ }^{(14)}$ found that neck pain is the most common site for musculoskeletal symptoms associated with microlaryngeal surgery with prevalence of $52 \%$. Also, Vaidya et al. ${ }^{(\mathbf{1 5})}$ found that $45 \%$ of surgeons reported neck pain, this low prevalence may be due to use small sample forming of 50 surgeons.

The NDI was used in this study to assess the effects of pain on the surgeons' lives, as well as degrees of disability, which ranged from mild, moderate to severe. The results demonstrated that $9 \%$ had no disability, $72.5 \%$ suffered from mild disability and $14.5 \%$ moderate disability. This results was lower than the work of Alem et al. ${ }^{(3)}$ who reported that $34.8 \%$ suffered from mild disability, $54.3 \%$ moderate disability, and $10.9 \%$ severe disability, and this may be due to limited age of our participants 30:40 years. Also this study agree with the study of Alem et al. ${ }^{(3)}$ who reported that the most affected daily activity were reading and headache.

The current study found positive correlation between musculoskeletal neck pain and number of operations, and There was a significant increase in the prevalence of workrelated neck pain in right-handed compared with that in left-handed ( $\mathrm{p}=0.02)$. This results agree with Rimmer $\boldsymbol{e t}$ $\boldsymbol{a l} .^{(13)}$ who found significant correlation between musculoskeletal symptoms attributed to the use of the endoscope or body posture during procedures and number of procedures performed per year. There was also a positive correlation between symptoms and being righthanded $(\mathrm{p}<0.01)$.

According to the result of the current study sex, BMI and using arm support were not significantly correlated with the prevalence of musculoskeletal neck pain, this is similar to work of Wong $\boldsymbol{e t}$ al. ${ }^{(\mathbf{1 4})}$ who found that there was no correlation between sex of the surgeons, Body mass index and experience of musculoskeletal symptoms, also there were no difference In musculoskeletal symptoms between arm support and non-arm support group.

According to the result of the study, there was a significant increase in the prevalence of work-related neck pain in subjects with 41- 60 clinical working hours/week compared with that in subjects with 10- 40 clinical working hours/week $(\mathrm{p}=0.005)$. This agrees with study by Bolduc-Bégin $\boldsymbol{e t} \boldsymbol{a l}^{\left({ }^{(12)}\right.}$ who reported that otolaryngologists who worked more than $16 \mathrm{~h}$ per week in clinic had a higher prevalence of global musculoskeletal symptoms $(p=0.028)$. Also agree with Lee $\boldsymbol{e t}$ al. ${ }^{(16)}$ who investigated the association between long working hours and work-related musculoskeletal 
symptoms among Korean wage workers. The results of analysis showed that as the working hours per week increased, the prevalence of upper and lower limb pain that workers experienced were also higher compared to the reference group of weekly working hours. The relationship between long working hours and the risk of WMSDs can be explained by the hypothesis that as the working hours increase, time exposed to the physical demands during work increases as well and this consequently could affect the higher prevalence of musculoskeletal diseases.

Anshul et $\boldsymbol{a l} .{ }^{(17)}$ reported that as the daily and weekly working hours increased, the complaints of neck pain increased. It has been thought that prolonged maintenance of an inappropriate body position while working in a limited area may impose excess loading on the cervical spine. But our results disagree with study by Barghout $\boldsymbol{e t}$ al. ${ }^{(18)}$ who found that there is no significant relationships between MSDs and each of height, weight, working hours. In this study, no relationship of statistical significance was identified between daily working hours and the prevalence of the investigated MSDs. This could be explained by the finding that the majority of dentists in this study (87\%) work between 5-8 hours per day.

The current study revealed that There was a significant increase in the prevalence of work-related neck pain in subjects with 8-16 experience years compared with that in subjects with 4- 7 experience years $(p=$ 0.005). this is similar to the result of Barghout et al. ${ }^{(18)}$ who reported that the prevalence of MSDs significantly increased with the increase of years of experience $(\mathrm{P} \leq$ $0.05)$. Neck, shoulder and back pain were more among dentists with more years of professional experience $(\mathrm{P} \leq 0.0001)$.

In this study the regression analysis determined Years of experience, number of operations/week, number of operating hours/week, clinical working hours and number of cases /week as predictors for neck pain.

\section{Limitation of this study}

The physical, psychological status and cooperation of the otolaryngologists.

\section{CONCLUSION}

It could be concluded that work related neck pain is high among Egyptian Otolaryngologists with prevalence of $69 \%$. This make us in need to improve ergonomics in the clinical and operative room settings and to educate otolaryngologists on ergonomic principles.

\section{REFERENCES}

1. Ho T, Hamill C, Sykes K et al. (2018): Work-related musculoskeletal symptoms among otolaryngologists by subspecialty: a national survey. The Laryngoscope, 128(3): 632640.

2. Dabholkar T, Yardi S, Dabholkar Y et al. (2017): A survey of work-related musculoskeletal disorders among otolaryngologists. Indian Journal of Otolaryngology and Head \& Neck Surgery, 69(2): 230-238.

3. Alem A, Abdalwassie L, Alharbi A et al. (2018): Neck Pain Among Otolaryngologists, Head and Neck Surgeons. Saudi Journal of Otorhinolaryngology Head and Neck Surgery, 20(2): 56-61.

4. Mohd A, Zailina H, Shamsul B et al. (2010): Neck, upper back and lower back pain and associated risk factors among primary school children. J Appl Sci., 10(5): 431-435.

5. Wang H, Naghavi M, Allen C et al. (2016): GBD 2015 Mortality and Causes of Death Collaborators. Global, regional, and national life expectancy, all-cause mortality, and causespecific mortality for 249 causes of death, 1980-2015: a systematic analysis for the Global Burden of Disease Study. Lancet, 388(10053):1459-1544.

6. Haldeman S, Carroll L, Cassidy J (2010): Findings from the bone and joint decade 2000 to 2010 task force on neck pain and its associated disorders. American College of Occupational and Environmental Medicine, 52:424-427

7. Cohen S (2015): Epidemiology, diagnosis, and treatment of neck pain. In Mayo Clinic Proceedings, 90(2): 284-299.

8. Childs J, Cleland J, Elliott J et al. (2008): Neck pain: clinical practice guidelines linked to the International Classification of Functioning, Disability, and Health from the Orthopaedic Section of the American Physical Therapy Association. Journal of Orthopaedic \& Sports Physical Therapy, 38(9): 1-34.

9. Mohan H, Ryan J, Whelan B et al. (2010): The Visual Analogue Scale and Verbal Numerical Rating Scale as pain assessment tools in the emergency department. Emerg Med J., 33: 372-5.

10. Macdermid J, Walton D, Avery S et al. (2009): Measurement properties of the neck disability index a systematic review. Journal of Orthopedic and Sports Physical Therapy, 39(5):40017.

11. Hoy D, Protani M, De R et al. (2010): The epidemiology of neck pain. Best Practice \& Research Clinical Rheumatology, 24(6):783-92.

12. Bolduc-Bégin J, Prince F, Christopoulos A et al. (2018): Work-related musculoskeletal symptoms amongst Otolaryngologists and Head and Neck surgeons in Canada. European Archives of Oto-Rhino-Laryngology, 275(1): 261-267.

13. Rimmer J, Amin M, Fokkens W et al. (2016): Endoscopic sinus surgery and musculoskeletal symptoms. Rhinology, 54(2): 105-10.

14. Wong A, Baker N, Smith L et al. (2014): Prevalence and risk factors for musculoskeletal problems associated with micro laryngeal surgery: a national survey. The Laryngoscope, 124(8): 1854-1861.

15. Vaidya A, Sainju N, Joshi S (2015). Work related musculoskeletal disorders among surgeons working in a tertiary care hospital in Kathmandu, Nepal. International Journal of Occupational Safety and Health, 5(2): 6-10.

16. Lee J, Kim G, Jung $S$ et al. (2018). The association between long working hours and work-related musculoskeletal symptoms of Korean wage workers: data from the fourth Korean working conditions survey (a cross-sectional study). Annals of Occupational and Environmental Medicine, 30(1): 67-69.

17. Anshul B, Parul B, Sandeep K et al. (2013): Prevalence of neck disability among dental professionals in north India. Journal of Evolution of Medical and Dental Sciences, 2(45): 8782-8787.

18. Barghout N, Al-Habashneh R, Al-Omiri M (2011). Risk factors and prevalence of musculoskeletal disorders among Jordanian dentists. Jordan Medical Journal, 171(779): 1-20. 